\title{
Recent Advancement of Clinical Information Systems: Opportunities and Challenges
}

\author{
Md. Mohaimenul Islam ${ }^{1,2}$, Tahmina Nasrin Poly ${ }^{1,2}$, Yu-Chuan (Jack) Li Li, 2,3 \\ 1 Graduate Institute of Biomedical Informatics, College of Medical Science and Technology, Taipei \\ Medical University, Taipei, Taiwan \\ 2 International Center for Health Information Technology, Taipei Medical University, Taipei, Taiwan \\ 3 TMU Research Center of Cancer Translational Medicine, Taipei, Taiwan
}

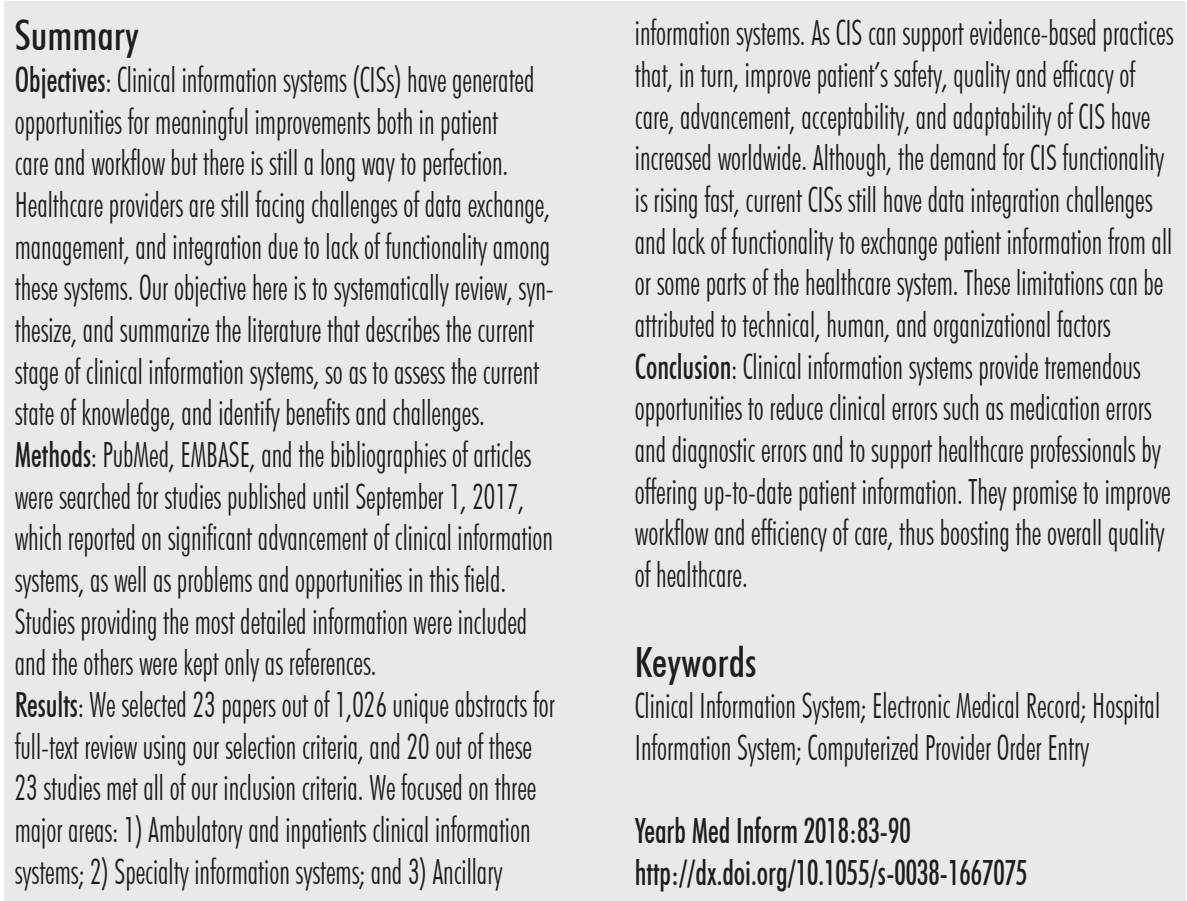

\section{Introduction}

Healthcare industry is underperforming despite having a record in spending, and major concerns have been raised due to a wide range of clinical errors [1]. The cost of these errors is mounting expenses from compensatory therapies, readmissions, and unnecessary tests. According to a study [2], clinical errors in the United States (US) cost about 19.5 billion dollars in 2008, of which 17 billion dollars were directly associated with added medical costs such as ancillary services, prescription drug services, and inpatient and outpatient care. In the US, more than 250,000 deaths per year have been attributed to medical errors which has become the third leading cause of death after heart disease and cancer [3].

Clinical information systems (CISs) are crucial to delivering the best in evidence-based, and patient-centered care [4]. It has great potential in reducing medical errors, increasing legibility, cutting unnecessary healthcare costs, and boosting the quality of healthcare. The major role of CISs is to capture, store, process, and timely transfer information to clinical decision makers for a correct and rapid decision $[5,6]$. For example, a CIS can easily import data from different instruments such as vital signs monitors, ventilators, and infusion devices, store them safely, and display them in specific tables and formats. One advantage of this type of systems is to interconnect with other subsystems in the hospital, e.g. pharmacy, different laboratories, radiology, and different image processing storage solutions [7]. A good CIS contributes positively to patient's safety, workflow efficiency, and to point-of-care decision support $[8,9]$. The development of CISs has posed some new challenges and, at the same time, has also generated new opportunities $[10,11]$.

As the healthcare industry is suffering from being a heterogeneous system made of disparate silos of data, with lack of standardization, healthcare providers are seeking a way to modernize their existing systems with novel CISs that allow storing, managing, and exchanging health information within and among hospitals. The efforts to implement better CISs have been intensified. Therefore, we conducted a review of published literature to provide information regarding the current state of CIS.

\section{Methods}

\section{Data Sources and Searches}

We performed a systematic review of the literature according to the PRISMA (Preferred Reporting Items for Systematic Reviews and Meta-Analyses) guidelines [12]. The relevant literature databases such 
as PubMed, EMBASE, Google, Google Scholar, and Scopus were searched for articles published until September 1, 2017, which report on the advancement of clinical information systems. We used the following words as search terms: "clinical information systems", "CIS", "Computerized provider order entry", "CPOE", "Inpatient electronic medical records", "Outpatient electronic medical record", "Emergency department information system", "ICU information system", "Cardiology information system", "Oncology information system", "Laboratory information system", "LIS", "Pharmacy information system", "PIS", "Radiology information system", "RIS", "Advancement of CIS", "Opportunity of CIS", and "Challenges of CIS". Table 1 provides an overview of our specific search strategies. The reference lists of all included full-text articles were searched to identify any studies missed in the initial search, and Google Scholar was used to find academic works citing eligible articles. Unpublished studies and references that only provided an abstract were not considered. References were compiled and managed using EndnoteX7 (Thomson Reuters), with duplicates removed using this software.

\section{Inclusion and Exclusion Criteria}

Two authors (MMI, TNP) who are experts in CIS independently scrutinized all titles and abstracts, and obtained full-texts of potentially relevant articles. In the initial stage, our selection criteria allowed the inclusion of any relevant study. Then, authors examined the retrieved articles independently, removed duplicates, and determined whether the study should be included or excluded. Studies had to meet the following inclusion criteria:

- Be published in English;

- Provide all information regarding to ambulatory and inpatient clinical information systems (electronic medical record and computerized provider order entry);

- Provide all information about specialty systems (intensive care unit information system, cardiology information system, oncology information system);

- Provide all information about ancillary information system (radiology information system, laboratory information system, and pharmacy information system);

Table 1 Summary of the study selection process

\begin{tabular}{|c|c|c|c|}
\hline Areas & Selected Keywords & Databases & $\begin{array}{l}\text { Number of } \\
\text { Identified } \\
\text { articles }\end{array}$ \\
\hline $\begin{array}{l}\text { Ambulatory and } \\
\text { Inpatient Clinical } \\
\text { Information Systems }\end{array}$ & $\begin{array}{l}\text { "Ambulatory electronic medical record", } \\
\text { "OPD electronic medical records"," } \\
\text { Inpatient clinical information system" } \\
\text {,Inpatients electronic medical record", " } \\
\text { computerized provider order entry" }\end{array}$ & $\begin{array}{l}\text { PubMed, EMBASE, } \\
\text { Google, Google } \\
\text { scholar, Scopus }\end{array}$ & 548 \\
\hline Specialty systems & $\begin{array}{l}\text { "ICU information system", } \\
\text { "Cardiology information system", } \\
\text { "Oncology information system" }\end{array}$ & $\begin{array}{l}\text { PubMed, EMBASE, } \\
\text { Google, Google } \\
\text { scholar, Scopus }\end{array}$ & 326 \\
\hline $\begin{array}{l}\text { Ancillary Information } \\
\text { Systems }\end{array}$ & $\begin{array}{l}\text { "Laboratory information system", } \\
\text { "Pharmacy information system", } \\
\text { "Radiology information system" }\end{array}$ & $\begin{array}{l}\text { PubMed, EMBASE, } \\
\text { Google, Google } \\
\text { scholar, Scopus }\end{array}$ & 152 \\
\hline
\end{tabular}

- Provide information about challenges and opportunities.

Studies were excluded if they met the following criteria:

- Be editorials, short communications, or case studies;

- Not published in English;

- No discussion on opportunities and challenges of clinical information systems.

\section{Data Extraction}

The same two authors (MMI, TNP) ensured the appropriateness of including studies in the final analysis. All discrepancies were resolved by consensus and discussed with the main investigator. In this stage, detailed information was extracted regarding:

- Current advancement of CISs;

- Classification of CISs;

- Opportunities of CISs;

- Challenges for implementing CISs;

- Infrastructure and information flows of CISs.

\section{Outcome Parameters}

The two outcome parameters of this survey report were: (1) to describe the status of clinical information systems; and (2) to identify the challenges and opportunities of clinical information systems.

\section{Results}

\section{Article Selection}

A total of 1,026 original articles were identified. Of these, 1,003 articles were excluded based on predetermined eligibility criteria described above, while the remaining 23 articles underwent detailed full-text evaluation. Among these, 20 met all of our inclusion criteria. Figure 1 summarizes the selection process.

\section{Infrastructure and Information Flows of Clinical Information Systems}

CISs are computer systems that provide immediate access to current patient data regarding clinical notes, medication history, laboratory reports, images, and reports either directly or via data networks. They are parts of a hospital information system, which facilitates direct patient care. An effective CIS warrants cost reduction, workflow improvement, and standardization of procedures. A CIS consists of a wide range of networking technology, clinical databases, electronic medical records, as well as other clinical informatics research evidence systems. Figure 2 provides a generic model of information flows among CISs. Information from various CISs is entered into an electronic health record. This information is then networked to different databases as needed. Clinical information from EHRs and different other systems is then exchanged for 
PRISMA 2009 Flow Diagram

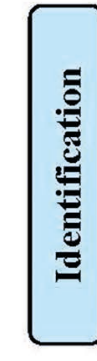

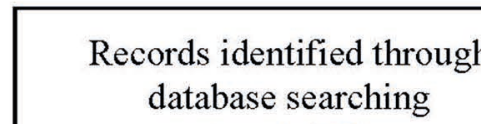

database searching

$$
(\mathrm{n}=1,025)
$$

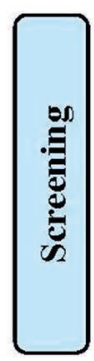

Records after duplicates removed

Additional records identified through other sources

$(\mathrm{n}=1)$
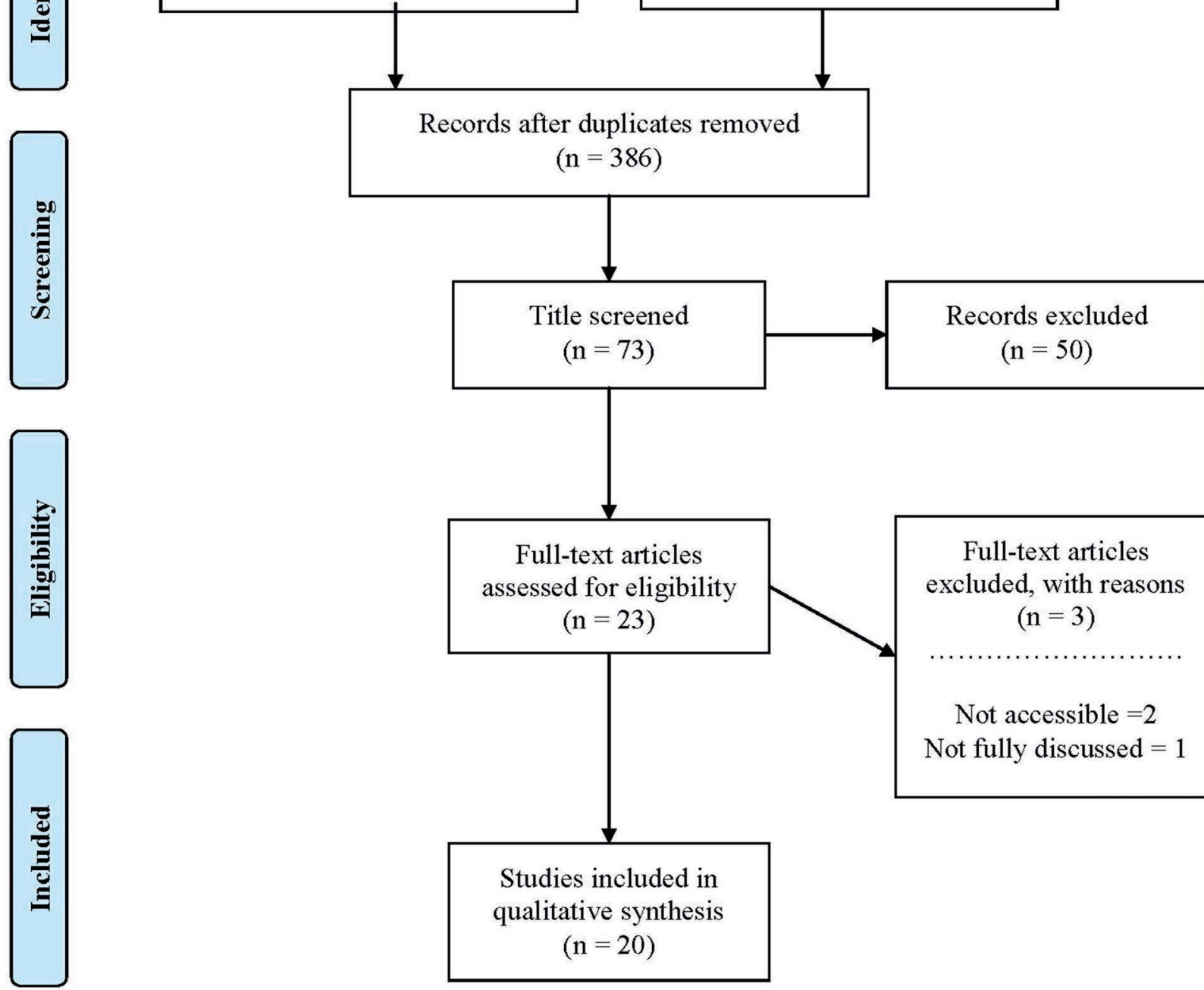

Full-text articles

Full-text articles assessed for eligibility $(\mathrm{n}=23)$

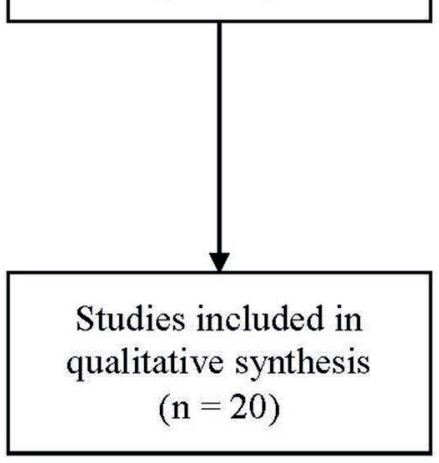

Not accessible $=2$

Not fully discussed $=1$

Fig. 1 Flowchart of the literature search (adapted from the PRISMA group 2009 flow diagram). 
proper and effective treatment, e.g., it may be used for effective decision-making. The United States Health Insurance Portability and Accountability Act (HIPAA) covers privacy and security provisions for safeguarding clinical information. All systems use the Health Level Seven (HL7) standard for proper exchange of a patient's information. A CIS is widely seen as a significant clinical component of hospital information system solutions. CISs have been changing rapidly and offering unique opportunities as well as challenges never experienced before. Both opportunities and challenges cut though technological, organizational, and human factors. However, the interaction between these factors is responsible for providing a more informative and rich lens for understanding the current and future landscape of CIS [13].

This paper focuses on three major areas of clinical information systems, namely, (1) ambulatory and inpatient clinical information systems; (2) specialty information systems; and (3) ancillary information systems.

\subsection{Ambulatory and Inpatient Clinical Information Systems \\ Electronic Medical Record}

An electronic medical record (EMR) is the infrastructure that spans across almost all CIS subsystems. EMRs are key components for ambulatory and inpatient clinical information systems [14]. In the U.S., the adoption rate of basic EMR systems among all providers has been increased from $9.4 \%$ in 2008 to $67 \%$ in 2017. Physician specialists with the highest adoption rates were $76 \%$ in internal medicine and pediatrics, followed by nephrology $(75 \%)$, family practice $(75 \%)$, and urology (74\%) [15]. Nowadays, patients' family history is being included into EMRs. This is useful to access potential disease risks and offer insight into the interplay between inherited and social factors relevant to patient care [16]. As some specific gene variants among person to person cause a specific disorder and are responsible for changing the effects of medications, the whole exome or genome sequencing data is being stored into EMRs [17]. Integration of biobanks with e-health records makes each resource more valuable and accelerates the translational pipeline, although helping to accurately identify subjects with specific diseases and phenotypes as well as identifying genotype-phenotype associations [18]. Evans et al. [19] mentioned that sophisticated care depends on various medical devices in order to monitor a patient's vital signs and additional information that is not specifically valuable for EMRs but is essential for clinical decision support applications to prevent adverse outcomes.

\section{Computerized Provider Order Entry}

Computerized provider order entry systems (CPOEs) are essential components of ambulatory and inpatient clinical information systems. They allow a physician to prescribe electronically, communicate with various departments (e.g. pharmacy, laboratory, radiol-

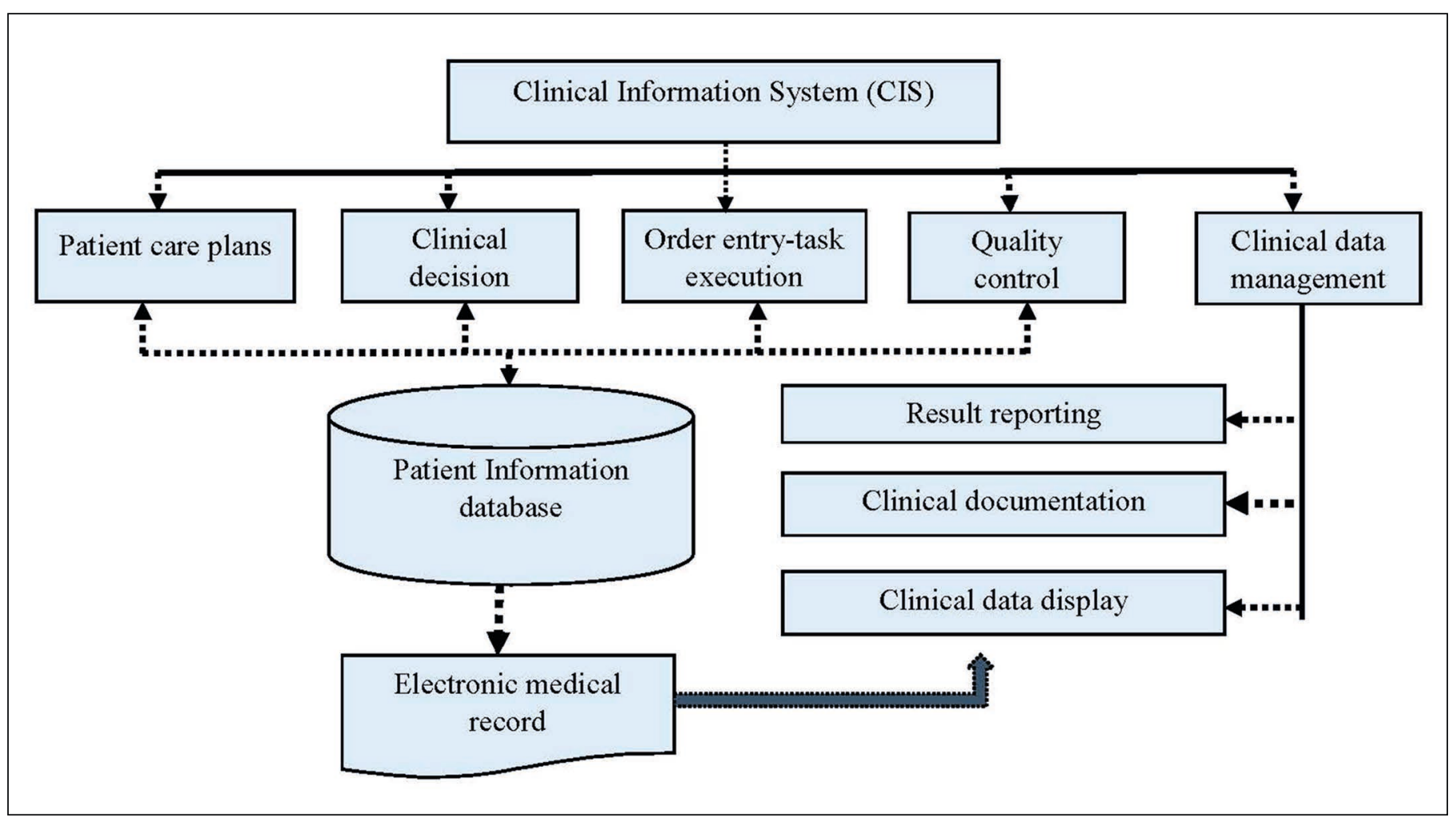

Fig. 2 Infrastructure and flows in clinical information systems. 
ogy, intensive care unit) and alert physicians on potential drug-drug or drug-allergy interactions. Nuckols et al. [20] reported that CPOEs were associated with half as many preventable adverse effects (pooled risk ratio $(\mathrm{RR})=0.47$, $\left.\mathrm{CI}_{95 \%}=[0.31,0.71]\right)$ and medication errors $\left(\mathrm{RR}=0.46, \mathrm{CI}_{95 \%}=[0.35,0.60]\right)$. They also mentioned implementing CPOEs with clinical decision support systems (CDSSs) could yield substantial long-term savings to society in the United States. However, the implementation and use of CPOEs with CDSSs is complex and fragile. A careful planning, implementation, and maintenance are required to get proper functionality otherwise this may create a potential safety risk. Nowadays, when leveraging a new technology, healthcare organizations are developing and using a risk assessment process to identify and evaluate unanticipated consequences and CPOE-generated errors. Elsaid et al. [21] mentioned that electronic chemotherapy prescribing reduced prescribing errors, reduced significant toxicities at clinically prescribed doses, but rose serious issues of drug safety. Also, Forrester et al. [22] demonstrated that over the five years' period, CPOEs cost $\$ 18$ million less than paper prescribing, and were associated with less than 1.5 million medication errors and 14,500 adverse drug effects [23].

\subsection{Specialty Information Systems} Intensive Care Unit Information Systems

Intensive care unit information systems (ICUISs) reduce physicians time spending on documentation and increase the time available for direct patient care by providing protocol templates and flow sheets [24]. They support the continuous assessment and adjustment of medication, the automatic capture of physiologic parameters from patient monitors, the display of patients' vital conditions, and the categorization of patients based on SOFA and APACHE score for proper decision-making. Ehteshami et al. [25] mentioned that ICUISs can improve practitioner satisfaction, quality of care, and cost-effectiveness. However, ICUISs should be integrated with health information systems (HISs), such as EMRs and patient monitoring systems, to maximize the benefits from ICUISs. Levesque et al. [26] reported that with the use of ICUISs, the time per admission and coding errors were reduced, from $6.8 \pm 2.8 \mathrm{~min}$ in 2007 to $3.6 \pm$ $1.9 \mathrm{~min}$ in $2008, \mathrm{p}<0.001$, and from $7.9 \%$ to. $2.2 \%, p<0.001$, respectively. Bosman et al. [27] reported a $30 \%$ reduction in documentation time (paper $20.5 \%$ of total nursing time vs. ICUIS $14.4 \%, \mathrm{p}<0.001)$. Levesque et al. [28] showed that the implementation of ICUISs allowed shortening ICU length of stay without altering other patient outcomes ( $8.4 \pm 15.2$ vs. $6.8 \pm 12.9$ days, $p=0.048)$. However, the use of an ICUIS changes medical and nursing activities, as well as influences cross-disciplinary communication during ICU ward rounds [29].

\section{Cardiology Information Systems}

Cardiovascular diseases have increased along with the demand for productive data management tools in the cardiac care departments. A cardiovascular information system (CVIS) plays a vital role in monitoring, management, evaluation, and policy development related to cardiac diseases [30]. A CVIS integrates all cardiology requests, procedures, images, and reports. When CVISs are integrated with other clinical information systems, physicians can extract images and reports from any computer inside and outside of the hospital through a portal. A CVIS can offer structured templates for echo, pediatrics, peripheral vascular, cath lab, and other systems. In addition, the demand for CISs has been increased with cardiovascular picture archiving and communication systems (CPACS) that provide effective data analysis and accurate therapeutic decisions in less time [31]. Additionally, hospital information systems are integrated with CVISs for exchanging 4D echocardiography, nuclear medicine, computed tomography (CT) angiography, and pediatric echocardiography reports. It is becoming evident that technological complexity, management of a large amount of data, data retrieval, and lack of skilled human resources in cardiology are creating the need for better CVISs [32].

\section{Oncology Information Systems}

The use of oncology information systems (OISs) has been increasing due to the complexity of new drugs and new radiation therapies, government regulations, and legal liability issues [33]. To ensure effective and efficient oncology treatment, OISs are crucial for measuring the rate of adoption and the effectiveness of practice standards as well as facilitate clinical practice and research [34]. These systems combine radiation, medical and surgical oncology information into a complete, oncology specific EMR, which help physicians to manage their patients' entire information from diagnosis through follow-up. Nielsen et al. mentioned five key parameters for usability of OISs:

1. Learnability (systems functionality is easy to learn);

2. Efficiency (functionality raises over the time which means the more advance a user is and that a higher productivity is achieved);

3. Memorability;

4. Minimized errors;

5. Increase satisfaction.

However, the success of OISs depends on several key factors including the need for change, physicians' leadership and engagement in the change process, workflow optimization, provision of the education and resources needed to implement $[35,36]$. Additionally, proficient knowledge and understanding of databases, and the collectivity of different subsystems should bring effective results. However, the free choice of implementation standards could lead to interoperability problems [37].

\subsection{Ancillary Information Systems}

\section{Radiology Information Systems}

Being able to easily integrate images into a report via the radiology information system (RIS) should improve healthcare providers' workflows as well as promote healthcare service quality, increase stakeholder satisfaction, improve total treatment quality, and gain competitive advantages [38]. Unification of RISs allows radiologists to easily get appropriate information for diagnosis in a unified workflow. The primary advantage of these systems lies in their ability to keep huge amounts of data readily accessible to ensure rapid workflow management and facilitate rapid communication. However, 
these systems only ensure high security, reliability, and privacy because they are only accessible by authorized physicians and technicians [39]. Additionally, picture archiving and communication systems (PACS) are central for clinical imaging and they process data from various medical devices such as computed radiography, CT scan, magnetic resonance imaging (MRI), and ultrasonography [40, 41]. Successful integration and interoperability among RISs and other systems such as EHRs, PACSs and LISs can create a flexible environment of data exchange/sharing, and provide more specific treatment options [42].

\section{Laboratory Information Systems}

Laboratory information systems (LIS) are computerized systems for rich sources of data that could be used for numerous purposes including operations, quality projects, and research [43]. They foster accuracy and accessibility to the flow of samples and data in clinical laboratories. Physicians may easily track each step in the testing process, from the administration of tests to the receipt of test results which supports timely decision-making and diagnosis [44]. It is important to enable bi-directional interfaces between LISs and other information systems such as EHRs to ensure a seamless flow of information ranging from test ordering to results storing for clinical decision support $[45,46]$. The integration of LISs with other systems is always challenging because of large hospital networks, technological complexity, interface design, and the multitude of clinical and laboratory workflows. The major challenges observed when implementing an interface between LISs and EHRs are the selection and harmonization of test codes, the communication with EHR providers, fluid orders and collection, problems with displaying laboratory results, the risk of missing abnormal flags, ordering specimens for anatomic pathology, and unanticipated changes to laboratory workflows $[14,47]$.

\section{Pharmacy Information Systems}

In recent years, the advancement of pharmacy information systems (PISs) has been gaining attention due to the reduction of clinical errors with intelligent warnings, messages, and rejection notices about medications. Also, PISs have been playing a vital role in preventing dosage errors by providing an individual dosage limit according to patient's age, gender, and other factors. Most importantly, PISs help to monitor drug-drug interactions, drug allergies, and various drug-related complications. Mahalli et al. [48] reported that the integration of a $\mathrm{CPOE}$ and a PIS has nearly eliminated the need for pharmacy staff to reenter medication orders from the CPOE system. The market size of PISs has been increasing due to their significant benefits and it is expected to grow at $7.7 \%$ from 2014 to 2019 . However, economic, cultural, and political challenges need to be addressed before all the benefits can be realized.

\section{Discussion}

Our study shows that clinical information systems clearly offer significant improvements to patient care. They are important tools in primary care for recording and managing patients' information in an efficient manner. They also support the organization of patients' demographic and clinical data; data storage and manipulation ensure overall care of the patients. In addition, managing clinical information through CISs helps to reduce prescription errors, unnecessary testing, and hospitalizations. CISs can support the meaningful and effective treatment of patients, and could improve safety, productivity, and healthcare outcomes.

\subsection{Major Opportunities}

The healthcare delivery system is changing in many ways. Technological advances are providing opportunities to optimize patient care. CISs have the potential to address many problems encountered in healthcare, namely, managing large amounts of patient and research data, reduce healthcare costs/ errors, increase legibility, and boost the quality of healthcare [13]. A physician can remotely, directly and timely, access (updates of) a patient's medical history supported by e.g. automatic sorting or summarization of clinical data [49]. By examining a patient's medical history in the context of relevant clinical research, physicians can take informed and evidence-based decisions. Optimal integration with other relevant systems in the HIS ensures that a CIS enhances communication among physicians, radiologists, pathologists, nurses, and other healthcare staff. This could lead to better clinical workflows, decision-making, reduction in adverse events, and ultimately, the improvement of the overall quality of care and patient safety $[50,51]$. For example, bi/multi-directional interfaces among CISs (LIS-EHR, RISEHR, PIS-her, etc.) enable a seamless flow of information from test/exam ordering to results presentation, and therefore facilitate faster test turnaround times resulting in quicker diagnosis for patients. CISs may also reduce test and medication errors through dose adjustment, dose range checking, therapeutic duplication checks, formulary alerts, drug-allergy, drugdrug and drug-laboratory interaction checks, and unnecessary test reminders [52]. Table 2 shows major opportunities for clinical information systems.

\subsection{Major Challenges}

CISs clearly offer excellent opportunities for improving care quality. Nevertheless, implementing CISs in healthcare organizations poses a series of challenges [53]. The adoption of IT in healthcare has been particularly slow and lagging behind as compared to other domains. This is due to the complexity in issues like interoperability, technological rationality, acceptability, managerial rationality, data security, data quality, and standards. A CIS typically provides a wide range of data repositories, medical reports, clinical decision support systems etc. that are generally not accessible in an integrated fashion. Further, current CISs implementations tend to have a lack of functionality to provide easy access and to create reminders [54]. In general, one can observe poor or even absent support for the exchange of patient-related information within the healthcare system, preventing immediate access to up-to-date and complete patient information. 
Table 2 Major opportunities for clinical information systems.

\begin{tabular}{|c|c|}
\hline $\begin{array}{l}\text { - Direct access to instant updates of a patient's medical } \\
\text { record as well as remote access to patients' records. }\end{array}$ & $\begin{array}{l}\text { - Improve quality and optimize the use of resources } \\
\text { throughout the health system. }\end{array}$ \\
\hline $\begin{array}{l}\text { - Healthcare professionals access to all information and } \\
\text { services they need in one place. }\end{array}$ & $\begin{array}{l}\text { - Development of efficient and intuitive data processing } \\
\text { software and bioinformatics tools. }\end{array}$ \\
\hline $\begin{array}{l}\text { - Patients-centric decision-making based on best clinical } \\
\text { evidence. }\end{array}$ & - Pleasurable and respectful interaction with users. \\
\hline $\begin{array}{l}\text { - Improve data quality and the analysis of a patient's data } \\
\text { by combining it with the physician's own knowledge. }\end{array}$ & $\begin{array}{l}\text { - Enhance communication among physicians, radiolo- } \\
\text { gists, pathologists, nurses, and other healthcare staff. }\end{array}$ \\
\hline - Development of better and more effective security protocols. & - Incorporation of IT professionals to the ICU. \\
\hline $\begin{array}{l}\text { - Faster test turnaround times to provide quicker diagnosis } \\
\text { for patients. }\end{array}$ & $\begin{array}{l}\text { - Greater chance to conduct potential research based on } \\
\text { reality. }\end{array}$ \\
\hline $\begin{array}{l}\text { - Utilization of a standard format to communicate with } \\
\text { different clinical information systems. }\end{array}$ & - Defense of value over volume. \\
\hline
\end{tabular}

Table 3 Major challenges of clinical information systems.

\begin{tabular}{|l|l|}
\hline - Development and integration among subsystems. & - Interoperability. \\
\hline $\begin{array}{l}\text { - Direct and indirect costs because of high initial investments } \\
\text { and low perceived return on investment. }\end{array}$ & $\begin{array}{l}\text { - Legacy systems that make clinical information systems' } \\
\text { workflows complex. }\end{array}$ \\
\hline - Interaction between administrative staff and physicians. & - Technical implication and data quality. \\
\hline - Competent project management team. & - Security and privacy. \\
\hline - Integration of precision medicine into the workflow. & $\begin{array}{l}\text { - Integration across disciplines and sufficient educational } \\
\text { resources. }\end{array}$ \\
\hline - Different data models among different vendors and sites. & $\begin{array}{l}\text { - Communication among a large number of clinicians } \\
\text { from multiple specialties. }\end{array}$ \\
\hline - Limited user capability to provide separate information for \\
quality measurement.
\end{tabular}

Major challenges of clinical information systems are given in Table 3.

\section{Conclusion}

Summarizing, there is an enormous potential for CISs to significantly improve clinical processes and even affect healthcare outcomes. The key benefits of CISs include reducing medical errors, improving clinical decision-making during patient encounters, and providing universal access to a patient's information in real time. However, to harvest the sweet benefits of CISs, one must address the major challenges and pitfalls during the systems. Additionally, healthcare organizations should adopt CISs to improve quality of care and to be able to stay competitive. The ultimate goal is to strike a balance between available resources, current HIS architecture, and the desired clinical improvement objectives. The quest to a perfect CIS is a long journey that is best started today.

\section{Conflict of interest: None} planning, design, and implementation of such

\section{References}

1. Graber ML. The incidence of diagnostic error in medicine. BMJ Qual Saf 2013 Oct;22 Suppl 2:ii21-ii27.

2. Andel C, Davidow SL, Hollander M, Moreno DA. The economics of health care quality and medical errors. Journal Health Care Finance 2012;39(1):39-50.

3. Makary MA, Daniel M. Medical error-the third leading cause of death in the US. BMJ 2016;353:i2139.

4. Doebbeling BN, Chou AF, Tierney WM. Priorities and Strategies for the Implementation of Integrated Informatics and Communications Technology to Improve Evidence-Based Practice. J Gen Intern Med 2006;21Suppl 2:S50-7.

5. Mackel J, Farris H, Mittman B, Wilkes M, Kanouse D. A Windows-based tool for the study of clinical decision-making. MEDINFO 1995;8 Pt2:1687.

6. Kushniruk AW, Patel VL. Cognitive and usability engineering methods for the evaluation of clinical information systems. J Biomed Inform 2004;37(1):56-76.

7. Balaraman P, Kosalram K. E-Hospital Management \& Hospital Information Systems-Changing Trends. International Journal of Information Engineering and Electronic Business 2013;5:50.

8. Moen A, Maeland Knudsen LM. Nursing informatics: decades of contribution to health informatics. Healthc Inform Res 2013;19(2):86-92.

9. Kavanagh KT, Cimiotti JP, Abusalem S, Coty MB. Moving Healthcare Quality Forward With Nursing-Sensitive Value-Based Purchasing. J Nurs Scholarsh 2012;44(4):385-95.

10. Paré G, Sicotte C, Jacques H. The effects of creating psychological ownership on physicians' acceptance of clinical information systems. J Am Med Inform Assoc 2006;13:197-205.

11. Haux R. Health information systems-past, present, future. Int J Med Inform 2006;75:268-81.

12. Moher D, Liberati A, Tetzlaff J, Altman DG. Preferred reporting items for systematic reviews and meta-analyses: the PRISMA statement. Int J Surg 2010;8(5):336-41.

13. Ngafeeson MN. Healthcare Information Systems Opportunities and Challenges; Encyclopedia of Information Science and Technology, Third Edition, IGI Global; 2015. p. 3387-95.

14. Petrides AK, Tanasijevic MJ, Goonan EM, Landman AB, Kantartjis M, Bates DW, et al. Top ten challenges when interfacing a laboratory information system to an electronic health record: Experience at a large academic medical center. Int J Med Inform 2017;106:9-16.

15. Zeng X. The impacts of electronic health record implementation on the health care workforce. N. C. Med J 2016;77(2):112-4.

16. Feero WG, Bigley MB, Brinner KM. New standards and enhanced utility for family health history information in the electronic health record: an update from the American Health Information Community's Family Health History Multi-Stakeholder Workgroup. J Am Med Inform Assoc 2008;15(6):723-8.

17. Kimball BC, Nowakowski KE, Maschke KJ, 
McCormick JB. Genomic data in the electronic medical record: Perspectives from a biobank community advisory board. J Empir Res Hum Res Ethics 2014;9(5):16-24.

18. Evans R. Electronic Health Records: Then, Now, and in the Future. Yearb Med Inform 2016 Suppl 1:S48-61.

19. Evans RS, Carlson R, Johnson KV, Palmer BK, Lloyd JF. Enhanced notification of infusion pump programming errors. Stud Health Technol Inform 2010;160:734-8.

20. Nuckols TK, Smith-Spangler C, Morton SC, Asch SM, Patel VM, Anderson LJ, et al. The effectiveness of computerized order entry at reducing preventable adverse drug events and medication errors in hospital settings: a systematic review and meta-analysis. Syst Rev 2014;3:56.

21. Elsaid KA, Garguilo S, Collins CM. Chemotherapy e-prescribing: opportunities and challenges. Integr Pharm Res Pract 2015;4:39-48.

22. Forrester SH, Hepp Z, Roth JA, Wirtz HS, Devine EB. Cost-effectiveness of a computerized provider order entry system in improving medication safety ambulatory care. Value Health 2014;17(4):340-9.

23. Klein L. Implementing an Advanced Computerized Provider Order Entry System to the Neonatal Intensive Care Using Kotter's Change Management Model. Canadian Journal of Nursing Informatics 2013;8

24. Mador RL, Shaw NT. The impact of a Critical Care Information System (CCIS) on time spent charting and in direct patient care by staff in the ICU: a review of the literature. Int J Med Inform 2009;78:435-45.

25. Ehteshami A, Sadoughi F, Ahmadi M, Kashefi P. Intensive care information system impacts. Acta Inform Med 2013;21(3):185-91.

26. Levesque E, Hoti E, de La Serna S, Habouchi $\mathrm{H}$, Ichai P, Saliba F, Set al. The positive financial impact of using an Intensive Care Information System in a tertiary Intensive Care Unit. Int J Med Inform 2013;82:177-84.

27. Bosman R, Rood E, Oudemans-van Straaten H, Van der Spoel J, Wester J, Zandstra D. Intensive care information system reduces documentation time of the nurses after cardiothoracic surgery. Intensive Care Med 2003;29:83-90.

28. Levesque E, Hoti E, Azoulay D, Ichai P, Samuel D, Saliba F. The implementation of an Intensive Care Information System allows shortening the ICU length of stay. J Clin Monit Comput 2015;29(2):263-9.

29. Fraenkel D. Clinical information systems in intensive care. Critical Care Resusc 1999;1(2):173.

30. McFarlane A, Wielgosz A. Strengthening information systems for heart health in Canada. Can J
Cardiol 2009;25(11):631-4.

31. Nolan PG. Planned implementation of an integrated Cardiovascular Information System in an Acute Hospital Group. [Masters dissertation]. Dublin: Royal College of Surgeons in Ireland; 2015.

32. Simoons M, van der Putten N, Wood D, Bassand J-P, Boersma E. The Cardiology Information System: the need for data standards for integration of systems for patient care, registries and guidelines for clinical practice. Eur Heart J 2002;23(15):1148-52.

33. Dahl R. Radiation Oncology Networking and Information Systems. American Association of Physicists in Medicine Annual Meeting; 2002 https://www.aapm.org/meetings/02am/pdf/762072080.pdf

34. Evans W, Ashbury FD, Hogue G, Smith A, Pun J. Implementing a regional oncology information system: approach and lessons learned. Curr Oncol 2014;21(5):224-33

35. de los Santos LEF, Herman MG. Radiation oncology information systems and clinical practice compatibility: Workflow evaluation and comprehensive assessment. Pract Radiat Oncol 2012;2(4):e155-e164.

36. Messados KV. Information technology in medicine. A structure analysis of a picture archive communication system (PACS) and a top down description of such a system in Hellenic University Hospital; 2014

37. Nyathi T, Colyer C, Bhardwaj AK, Rijken J, Morton J. Post-upgrade testing on a radiotherapy oncology information system with an embedded record and verify system following the IAEA Human Health Report No. 7 recommendations. Phys Med 2016;32(6):854-8.

38. Zhang J, Lu X, Nie H, Huang Z, van der Aalst WM. Radiology information system: a workflow-based approach. Int J Comput Assist Radiol Surg 2009;4(5):509-16.

39. Pereira AG, Vergara LG., Merino EAD, Wagner A. Solutions in radiology services management: a literature review. Radiol Bras 2015;48(5):298-304.

40. Bidgood WD Jr, Horii SC, Prior FW, Van Syckle DE. Understanding and using DICOM, the data interchange standard for biomedical imaging. J Am Med Inform Assoc 1997;4:199-212.

41. Nance JW Jr, Meenan C, Nagy PG. The future of the radiology information system. AJR Am J Roentgenol 2013;200(5):1064-70.

42. Clunie DA, Dennison DK, Cram D, Persons KR, Bronkalla MD. Technical Challenges of Enterprise Imaging: HIMSS-SIIM Collaborative White Paper. J Digit Imaging 2016;29(5):583-614.

43. Sepulveda JL, Young DS. The ideal laboratory information system. Arch Pathol Lab Med
2013;137(8):1129-40.

44. Lukić V. Laboratory Information System-Where are We Today? J Med Biochem 2017

45. McCudden CR, Henderson M. Laboratory information system data extraction and re-use: opportunities and challenges. J Lab Precis Med 2017;2

46. Birkner CC, Eldahdah EG, Kirkland HA, Martinez DF. Computerized laboratory information management system. Google Patents; 2004,

47. Blaya JA, Shin SS, Yagui MJ, Yale G, Suarez $\mathrm{CZ}$, Asencios LL, et al. A web-based laboratory information system to improve quality of care of tuberculosis patients in Peru: functional requirements, implementation and usage statistics. BMC Med Inform Decis Mak 2007;7:33.

48. Mahalli AE, Sahar H, Yamani W. Assessment of pharmacy information system performance in three hospitals in Eastern Province, Saudi Arabia. Perspect Health Inf Manag 2016;13

49. Woods SS, Schwartz E, Tuepker A, Press NA, Nazi KM, Turvey CL, et al. Patient experiences with full electronic access to health records and clinical notes through the My HealtheVet Personal Health Record Pilot: qualitative study. J Med Internet Res 2013;15(3):e65.

50. Lakbala P, Dindarloo K. Physicians' perception and attitude toward electronic medical record. Springerplus 2014;3:63.

51. Bowens FM, Frye PA, Jones WA. Health information technology: integration of clinical workflow into meaningful use of electronic health records. Perspect Health Inf Manag 2010;7:1d.

52. Garg AX, Adhikari NK, McDonald H, Rosas-Arellano MP, Devereaux P, Beyene J, et al. Effects of computerized clinical decision support systems on practitioner performance and patient outcomes: a systematic review. JAMA 2005;293:1223-38.

53. Mahmoud E, Rice G. Information systems technology and healthcare quality improvement. Review of Business 1998;19:8.

54. Wright A, Sittig DF. SANDS: a service-oriented architecture for clinical decision support in a National Health Information Network. J Biomed Inform 2008;41:962-81.

\section{Correspondence to:}

Yu-Chuan (Jack) Li, MD, PhD

Prof. College of Medical science and Technology

Department of Biomedical Informatics.

Taipei Medical University

250-Wuxing Street

Xinyi District

Taipei 11031, Taiwan

E-mail: jaak88@gmail.com; jack@tmu.edu.tw 